\title{
A Semliki Forest virus expression system as a model for investigating the nuclear import and export of hepatitis B virus nucleocapsid protein
}

\author{
A. ZAJAKINA, R. BRŪVERE, T. KOZLOVSKA \\ Latvian Biomedical Research and Study Centre, Ratsupites Str. 1, Riga, Latvia, LV-1067
}

Received October 4, 2013; accepted May 5, 2014

\begin{abstract}
Summary. - HBV core protein $(\mathrm{HBc})$, the major component of nucleocapsid is known to have an essential role in the virus life cycle as the transporter of virus genome to the host nucleus; however, molecular details of the intracellular transport of $\mathrm{HBc}$ remain unknown. In this study, we investigated the intracellular distribution of the $\mathrm{HBc}$ protein resulting from Semliki Forest virus (SFV)-driven $\mathrm{HBc}$ gene and HBV RNA pregenome (pgRNA) expression in BHK-21 cells. Fluorescent confocal microscopy revealed extensive HBc protein synthesis in the cytoplasm $12 \mathrm{hr}$ post infection (p.i.) with recombinant pSFV1/HBc or pSFV1/HBVpgRNA viruses. Twenty-four hr p.i., the $\mathrm{HBc}$ protein showed asymmetric, predominantly nuclear localization in most cells. However, $42 \mathrm{hr}$ p.i., the number of cells containing intranuclear $\mathrm{HBc}$ protein, dramatically decreased to $\sim 5 \%$, while cytoplasmic $\mathrm{HBc}$ protein was detected in all cells. Remarkably, $24 \mathrm{hr}$ p.i. with pSFV1/HBVpgRNA virus, cytoplasmic HBc protein colocalized with $\mathrm{HBs}$ protein. We conclude that a $\mathrm{HBs}-\mathrm{HBc}$ interaction partially prevents the transport of $\mathrm{HBc}$ from the cytoplasm to nucleus. The SFV-driven system can be used for identification of new factors involved in the HBV nuclear import and export.
\end{abstract}

Keywords: hepatitis B virus; nucleocapsid protein; surface protein; pregenomic RNA; Semliki Forest virus

\section{Introduction}

Hepatitis B virus (HBV) is a small double-stranded DNA virus (the Hepadnaviridae family, the Orthohepadnavirus genus), that causes both acute and chronic hepatitis in humans (Peppa and Maini, 2012). Many aspects of HBV biology remain unknown, hampering the development of effective antiviral therapy. Furthermore, the early events of HBV infection and genome transport to the nucleus are difficult to analyze because of the lack of a susceptible cell line model.

The nucleocapsid is thought to deliver the partially double-stranded HBV DNA genome to the nucleus, where the covalently closed circular HBV DNA genome (cccDNA)

E-mail: Anna@biomed.lu.lv; phone: +371-2808004.

Abbreviations: cccDNA = covalently closed circular DNA; $\mathrm{HBc}=$ core protein $; \mathrm{HBs}=$ surface protein; $\mathrm{HBV}=$ hepatitis $\mathrm{B}$ virus; pgRNA = RNA pregenome; SFV = Semliki Forest virus; ER $=$ endoplasmic reticulum; p.i. $=$ post infection; $\mathrm{RT}=$ room temperature is synthesized (Ganem and Prince, 2004). However, it is unknown whether the nucleocapsid particle is able to cross the nuclear membrane and enter the nucleus or disassembles prior to entry. Because HBV nucleocapsid particles were found in both the nucleus and cytoplasm of the hepatocytes from HBV-infected patients (Michalak and Nowoslawski, 1977; Petit and Pillot, 1985), it is possible that intact nucleocapsid particles are able to move in one or both directions across the nuclear membrane.

$\mathrm{HBV}$ replicates via pgRNA transcribed from cccDNA in the nucleus of an infected cell (Beck and Nassal, 2007). After export to the cytoplasm, pgRNA serves as a translational template for the synthesis of $\mathrm{HBc}$ and viral polymerase (Pol). HBc forms an isometric 27-nm capsid (core particle) together with encapsidated pgRNA and Pol. The shell of the capsid contains 180 or 240 identical capsid protein subunits of $21.5 \mathrm{kDa}$ (Crowther et al., 1994). Reverse transcription of pgRNA and the subsequent synthesis of an incomplete second strand of DNA generate the mature genome inside the newly formed cytoplasmic capsids. There is also evidence 
that mature capsids may transport the DNA genome back to the nucleus, thus enriching the pool of intranuclear cccDNA; some experimental data support this idea of retrograde transport of the HBV genome through $\mathrm{HBc}$ interaction with the nuclear pore complex (Schmitz et al., 2010; Rabe et al., 2009). Alternatively, in the presence of a sufficient amount of envelope proteins - HBV surface proteins (HBs), including small, middle, and large forms of the outer envelope components -translated from their own mRNAs, the nucleocapsids are segregated into the secretory pathway via the interaction with HBs proteins on the membrane of the endoplasmic reticulum (Bruss, 2007).

Although basic information on the role of the HBV capsid has been published, the signals and mechanism of such intracellular capsid segregation between nuclear and secretory pathways remain unknown. Recombinant plasmids based on the SFV genome have been introduced to express foreign genes in a broad range of eukaryotic cells (Liljestrom and Garoff, 1991; Zajakina et al., 2008), and the universal nature of the system makes it ideal for the investigation of HBV protein interaction and transport. In this study, we attempted to determine the intracellular distribution of $\mathrm{HBC}$ protein expressed from recombinant SFV carrying $\mathrm{HBc}$ gene or HBVpgRNA. The used SFV system proved suitable for identification of viral and host factors involved in regulation of HBV life cycle.

\section{Materials and Methods}

Cells. BHK-21 cells (ATCC, Sweden) were grown in BHK medium (Gibco-BRL) containing 5\% FCS, 10\% tryptose phosphate broth, $20 \mathrm{mmol} / \mathrm{l} \mathrm{HEPES}$, and $2 \mathrm{mmol} / \mathrm{l}$ glutamine. The cells were incubated in a $5 \% \mathrm{CO}_{2}$ atmosphere at $37^{\circ} \mathrm{C}$.

Vector constructs. The vector constructs used in this study were described previously (Zajakina et al., 2004; Kozlovska et al., 2004). Briefly, pSFV1/HBVpgRNA was generated by insertion of the fulllength cDNA copy of HBV pgRNA (genotype D1) into the SmaI restriction site of the pSFV1 vector (Liljestrom and Garoff, 1991), whereas $\mathrm{pSFV} 1 / \mathrm{HBc}$ was obtained by insertion of the $\mathrm{HBc}$ gene into the BamHI/SmaI restriction sites of the $\mathrm{pSFV} 1$ vector.

Recombinant SFVs. Recombinant alphaviruses were produced as previously described (Vasilevska et al., 2012). Briefly, RNA transcripts were produced in vitro from NruI-linearized pSFV1/ HBVpgRNA and SpeI-linearized pSFV1/HBc constructs. For the in vivo packaging of recombinant RNA into SFV particles, in vitro transcribed RNA was co-electroporated into BHK-21 cells together with SFV helper RNA (Liljestrom and Garoff, 1991). After $24 \mathrm{hr}$, the SFV particles from the culture medium were collected. The infection of BHK-21 cells was performed in a serum-free medium. The virus titers were determined by infecting BHK-21 cells with serial dilutions of the stocks, followed by an indirect immunocytochemistry assay for detection of $\mathrm{HBc}$ protein. The titers achieved were from $1 \times 10^{7}$ to $5 \times 10^{7}$ viral particles per $\mathrm{ml}$ and were used at $\mathrm{MOI}=10$.

Immunofluorescent staining of HBc and HBs. BHK-21 cells grown on chamber slides (NUNC A/S) were infected with recombinant SFV particles as previously described (Vasilevska et al., 2012) and incubated at $37^{\circ} \mathrm{C}\left(5 \% \mathrm{CO}_{2}\right)$ for $12 \mathrm{hr}, 24 \mathrm{hr}$, and $48 \mathrm{hr}$. The cells were then fixed in $4 \%$ paraformaldehyde solution (Sigma-Aldrich, USA) for $10 \mathrm{~min}$ at room temperature (RT), rinsed three times in PBS, immersed in PBS supplemented with $0.25 \%$ Triton X-100 for $10 \mathrm{~min}$, and rinsed with PBS again. A blocking solution containing $3.5 \%$ of FCS diluted in PBS was added, and the cells were incubated for $30 \mathrm{~min}$ at RT. Cells were incubated with primary rabbit anti$\mathrm{HBc}$ antibodies (Abcam, UK) at a dilution of 1:700 (in PBS with $3.5 \%$ FCS) overnight at $4^{\circ} \mathrm{C}$. The cells were washed three times with PBS and incubated in the dark for $1 \mathrm{hr}$ with an anti-rabbit IgG TRIC conjugate (Sigma-Aldrich, USA) diluted 1:350 in PBS supplemented with $3.5 \%$ FCS (RT). After rinsing with PBS, the cell nuclei were counterstained with DAPI solution $(300 \mathrm{nmol} / \mathrm{l}$ in PBS), and the cells were mounted in Prolong Gold Antifade Reagent (Molecular Probes, USA). For double anti-HBc/anti-HBs staining, the cells were stained with rabbit anti-HBc antibodies and the anti-rabbit IgG TRIC conjugate as described above, washed with PBS, and stained with 1:1000-diluted monoclonal anti-HBs 1-9C1 antibodies (a gift from Dr. I. Sominska) and a 1:200-diluted antimouse IgG FITC conjugate (Dako, USA). The staining evaluation was performed under a confocal fluorescent microscope (Leica TCS Sp2 SE) using the appropriate filters. To determine the subcellular regions of protein co-localization and intranuclear distribution, individual red-, green-, and blue-stained images derived from the same field were merged using Photoshop 6.0. The areas of $\mathrm{HBc} /$ HBs co-localization appear yellow.

\section{Results}

\section{Intracellular distribution of $H B c$ protein expressed by recombinant $\mathrm{pSF} / \mathrm{HBc}$ virus}

To investigate the intracellular distribution of the $\mathrm{HBC}$ protein, BHK-21 cells were infected with recombinant pSFV1/HBc virus encoding the full-length $\mathrm{HBc}$ gene. For microscopy studies, the cells were immunostained with rabbit anti-HBc antibodies and TRIC-conjugated anti-rabbit serum at various time points after infection $(12 \mathrm{hr}, 24 \mathrm{hr}$, and $42 \mathrm{hr}$ ). The red staining of the infected cells was visualized using a Leica DM 6000 B microscope. As shown in Fig. 1a, a strong nuclear localization of $\mathrm{HBc}$ was observed $24 \mathrm{hrs}$ p.i., whereas a preferentially cytoplasmic distribution of $\mathrm{HBc}$ was found at early and late p.i. times.

The microscopy results revealed nuclear $\mathrm{HBc}$ protein transport within the cell. Using the SFV expression system, recombinant protein synthesis began in the cell cytoplasm 
(a)

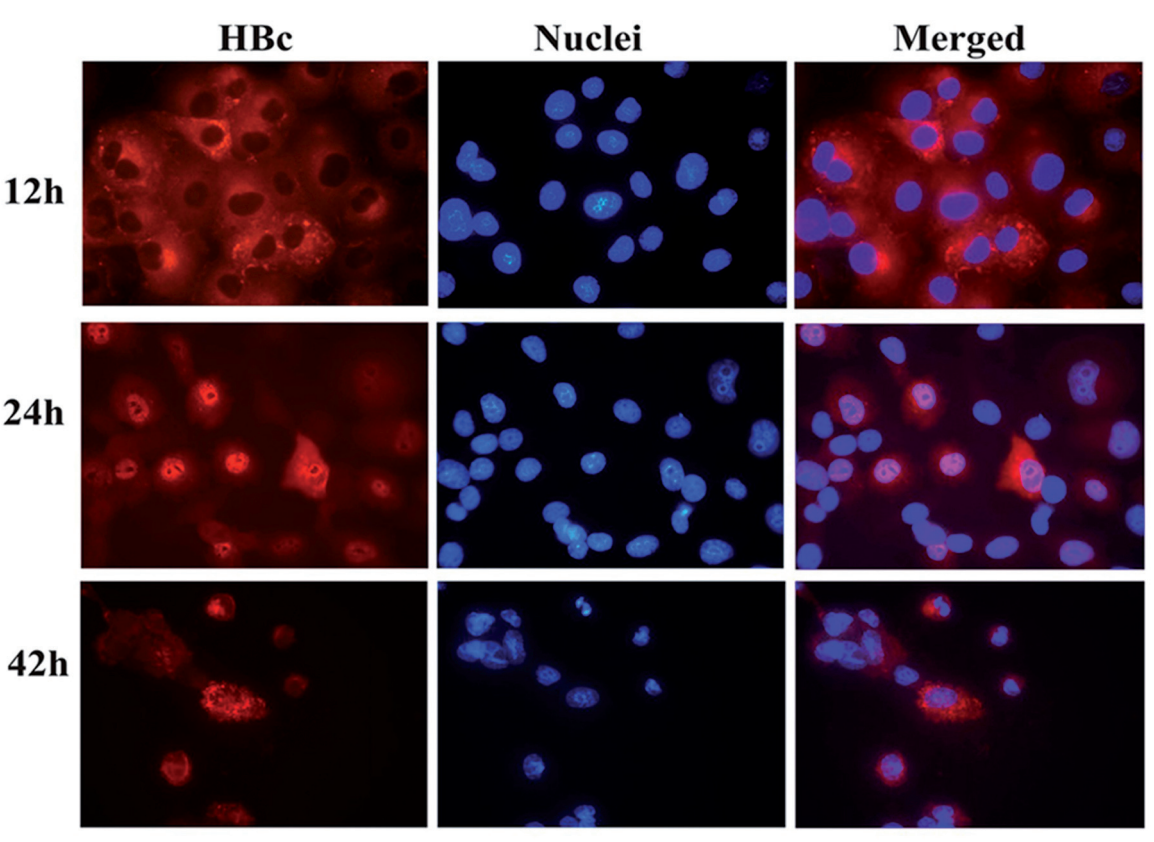

(b)

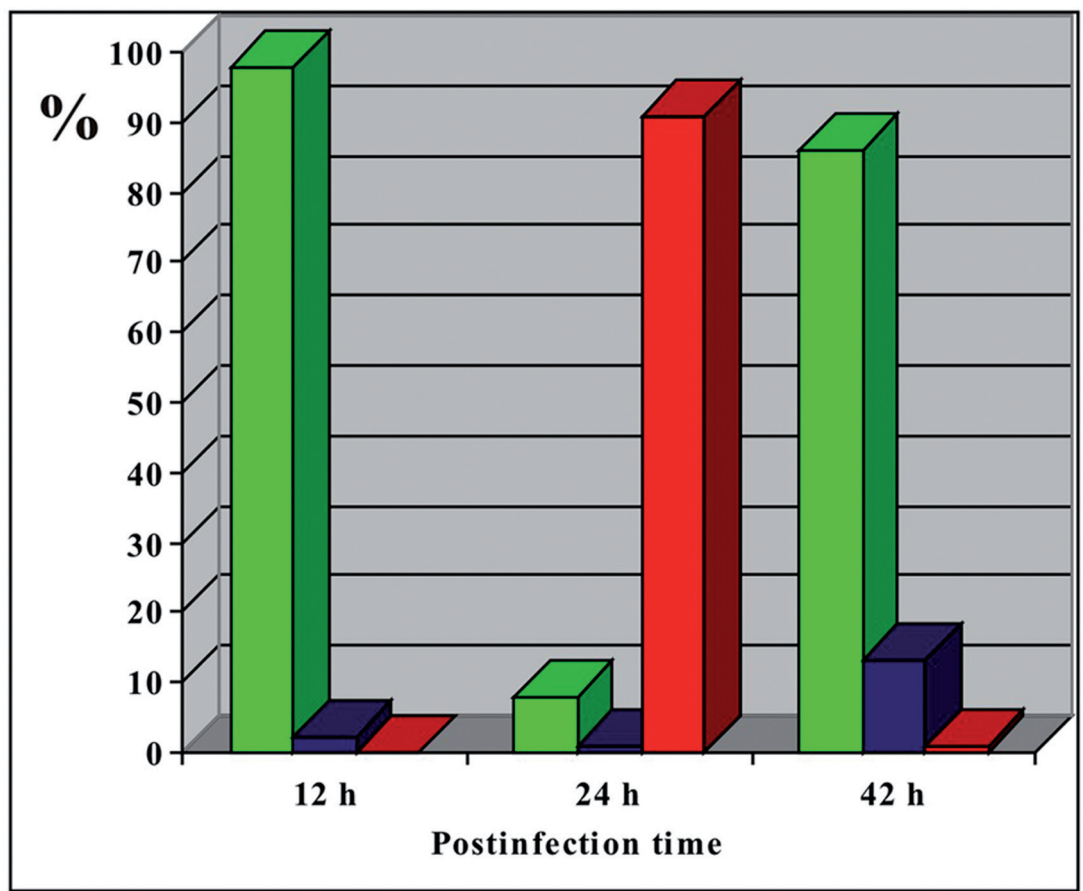

$\square$ HBc in cytoplasm $\square$ HBc in nucleus\&cytoplasm $\square$ HBc in nucleus

Fig. 1

Subcellular localization of $\mathrm{HBc}$ protein expressed by recombinant $\mathrm{pSFV} 1 / \mathrm{HBc}$ virus

BHK-21 cells were infected with recombinant $\mathrm{pSFV} 1 / \mathrm{HBc}$ virus and $\mathrm{HBc}$ was observed by immunofluorescent microscopy at different times after infection (for details see Materials and Methods). (a) Immunofluorescent microscopy. Staining: HBc (red), nuclei (blue). (b) Distribution of HBc between the cytoplasm and nucleus. The diagram shows the average \% of HBc-positive cells in cytoplasm only, in nucleus and cytoplasm, in nucleus only. The experiments were performed in triplicate. The standard error of three independent experiments did not exceed 5\%. 
(a)
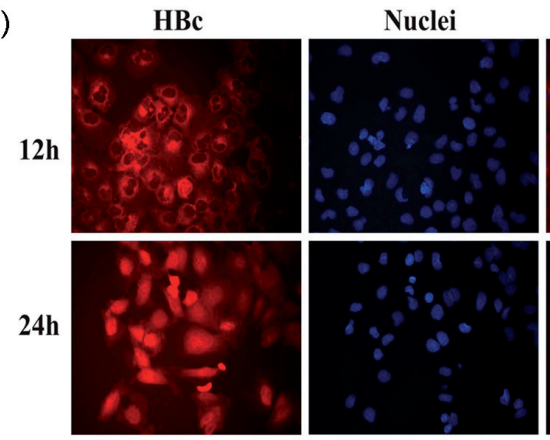

$42 \mathrm{~h}$
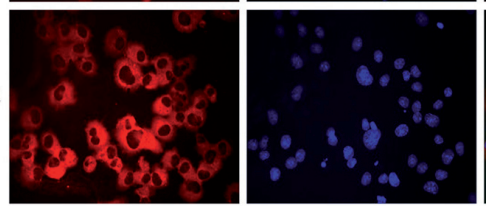

(b)

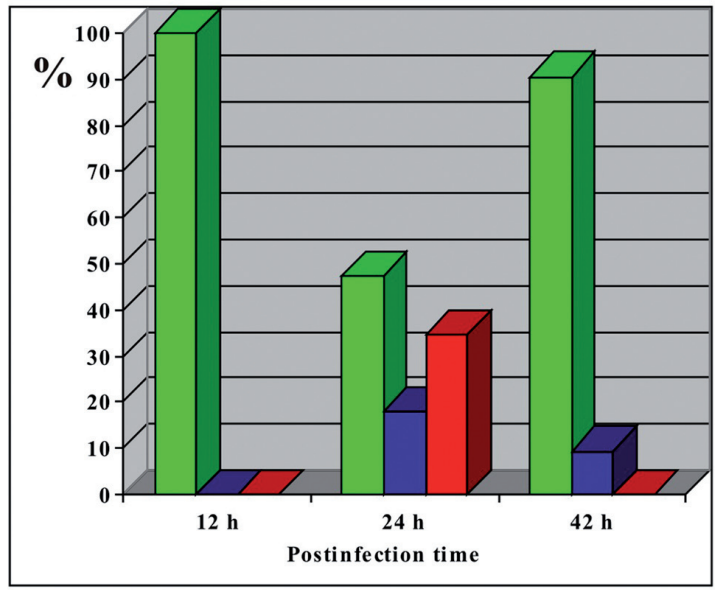

$\square$ HBc in cytoplasm $\square$ HBc in nucleus\&cytoplasm $\square$ HBc in nucleus

Fig. 2

Subcellular localization of $\mathrm{HBc}$ protein expressed by recombinant pSFV1/HBVpgRNA virus

BHK-21 cells were infected with recombinant pSFV1/HBVpgRNA virus and $\mathrm{HBc}$ was observed by immunofluorescent microscopy at different times after infection (for details see Materials and Methods). (a) Immunofluorescent microscopy. Staining: $\mathrm{HBc}$ (red), nuclei (blue). (b) Distribution of $\mathrm{HBc}$ between the cytoplasm and nucleus. The diagram shows the average $\%$ of HBc-positive cells in cytoplasm only, in nucleus and cytoplasm, in nucleus only. The experiments were performed in triplicate. The standard error of three independent experiments did not exceed $5 \%$.

$6 \mathrm{hr}$ p.i., with maximum synthesis $20-30 \mathrm{hr}$ p.i. Our observations show that approximately $98 \%$ of the cells contained cytoplasmic $\mathrm{HBc} 12$ hr p.i. (Fig. 1b). Twenty-four hours p.i., most cells (91\%) contained $\mathrm{HBc}$ exclusively in the nucleus, indicating the efficient intracellular transport and nuclear accumulation of $\mathrm{HBc}$. However, at a late p.i. time (42 hr and thereafter), most of the nuclei were again negative, whereas the cytoplasm ( $80 \%$ of cells) was $\mathrm{HBc}$ protein positive.
A small number of cells contained $\mathrm{HBc}$ both in the nucleus and cytoplasm (Fig.1b). Therefore, the $\mathrm{HBc}$ protein was found to have strong nuclear tropism $24 \mathrm{hr}$ p.i.

\section{Intracellular distribution of $H B c$ protein expressed by} recombinant $p S F V 1 / H B V p g R N A$ virus

In native $\mathrm{HBV}$ infection, pgRNA serves as a template for $\mathrm{HBc}$ protein expression with further encapsidation of pgRNA into the core particles. The reverse transcription of pgRNA to a DNA genome and its transport to the nucleus is a key step in the HBV infection cycle. In contrast, the mature core particles are subjected to segregation to the ER following HBs protein interaction for viral particle formation. To investigate the intracellular localization of $\mathrm{HBc}$ protein expressed from the entire pgRNA molecule, BHK-21 cells were infected with recombinant pSFV1/HBVpgRNA virus.

Immunofluorescence microscopy was performed using rabbit anti-HBc antibodies and an anti-rabbit-TRIC conjugate. The $\mathrm{HBc}$ protein distribution between the nucleus and cytoplasm was evaluated at various time points after infection (12 hr, $24 \mathrm{hr}$, and $42 \mathrm{hr}$ ). As shown in Fig. 2a, most cells contained $\mathrm{HBc}$ only in the cytoplasm at the early and late p.i. times. Conversely, as was observed for the pSFV1/HBc virus, $\mathrm{HBc}$ was found in the nucleus $24 \mathrm{hr}$ p.i., indicating strong nuclear tropism of $\mathrm{HBC}$ at this time point.

There was no major difference with regard to the localization of $\mathrm{HBc}$ expressed by the pSFV1/HBc and pSFV1/HBVpgRNA viruses. Indeed, the nuclear localization of $\mathrm{HBc}$ was detected at the middle $(24 \mathrm{hr})$ p.i. time for both recombinant viruses. However, in the case of pgRNA, an important percentage of the cells accumulated $\mathrm{HBc}$ both in the nucleus and in the cytoplasm (12\%) or only in the cytoplasm (43\%) $24 \mathrm{hr}$ p.i. (Fig. 2b), compared to the preferential nuclear localization (91\%) of HBc expressed by the $\mathrm{pSFV} 1 / \mathrm{HBc}$ virus. These observations indicate that a portion of the cells expressing pgRNA retained $\mathrm{HBc}$ in the cytoplasm, thus preventing its nuclear translocation.

Intracellular distribution of $H B c$ and $H B$ s proteins expressed by recombinant $p S F V 1 / H B V p g R N A$ virus

As was shown previously, the expression of HBV pgRNA by the pSFV1 expression vector allows the synthesis of all HBV structural proteins (Zajakina et al., 2004), including $\mathrm{HBc}$ and three variants of envelope (HBs) proteins: S, M, and $\mathrm{L}$. As the $\mathrm{HBc}$ capsid interacts with HBs protein residing on the membrane of the ER to form the HBV virion (Patient et al., 2009), it is possible that $\mathrm{HBc}$ retention in the cell cytoplasm at the middle p.i. time was influenced by capsid interaction with envelope proteins in this experimental system.

To confirm this idea, double immunostaining in BHK-21 cells infected with pSFV1/HBVpgRNA was performed using 


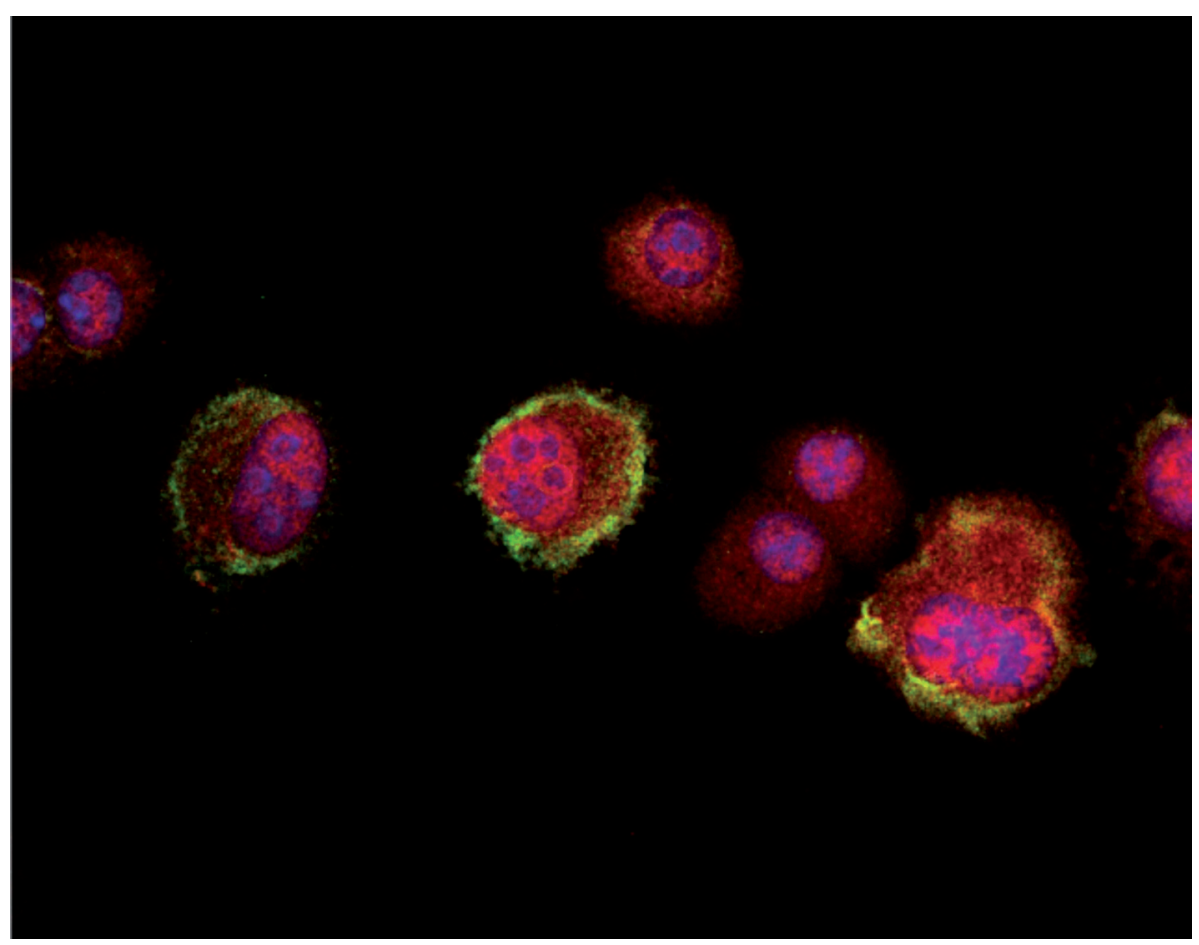

Fig. 3

Colocalization of $\mathrm{HBc}$ and $\mathrm{HBs}$ proteins expressed by recombinant $\mathrm{PSFV} 1 / \mathrm{HBVpgRNA}$ virus

BHK-21 cells were infected with recombinant pSFV1/HBVpgRNA virus and HBc and HBs were observed by immunofluorescent microscopy 24 hr p.i (for details see Materials and Methods). Staining: HBc (red), HBs (green), HBc + HBs colocalized (yellow), and nuclei (blue).

anti-HBc and anti-HBs antibodies, followed by fluorescence microscopy. The analysis revealed the prevalence of $\mathrm{HBc}$ expression in most cells $24 \mathrm{hr}$ p.i. However, some cells were positive for both $\mathrm{HBc}$ and $\mathrm{HBs}$ proteins, and these cells were subjected to $\mathrm{HBc} / \mathrm{HBs}$ colocalization studies under confocal microscopy. As shown in Fig. 3, the HBs protein was found in the cytoplasm in the perinuclear area and/or distributed asymmetrically in the cytoplasm. The confocal microscopy revealed the colocalization of $\mathrm{HBs}$ (green staining) and $\mathrm{HBC}$ (red staining) in the cytoplasm. The colocalization of both proteins confirms their interaction in the cell cytoplasm, which may prevent $\mathrm{HBc}$ transport into the nucleus. Therefore, some cells expressing $\mathrm{HBs}$ partially retain $\mathrm{HBc}$ in the cytoplasm.

\section{Discussion}

Herein, we describe the intracellular distribution of $\mathrm{HBC}$ protein expressed by the pSFV1 vector. $\mathrm{HBc}$ protein translocation to the nucleus within a short period of time (24 hr) was detected for both the pSFV1/HBVpgRNA and pSFV1/ $\mathrm{HBC}$ recombinant viruses. The strong nuclear tropism and accumulation of $\mathrm{HBc}$ in the nucleus correlates well with previous ultrastructural and immunohistochemical studies of HBV-infected liver tissues. In chronically infected patients with mild hepatitis, the core protein accumulates preferentially in the nucleus, whereas it is mainly detected in the cytoplasm of hepatocytes in patients with active disease (Chu and Liaw, 1995; Gowans et al., 1985; Naoumov et al. 1990; Serinoz et al., 2003) and may be associated with inflammation and immune hepatocytolysis.

Despite numerous investigations, the mechanism of $\mathrm{HBc}$ translocation and the role of its nuclear accumulation remain unclear. According to the cell division concept, during the premitotic phase, $\mathrm{HBc}$ is transported across the nuclear membrane as monomers or dimers, accumulating and forming capsids in the nucleus. During mitosis, when the nuclear membrane dissolves, the core particles are released into the cytoplasm and cannot reenter the nucleus, most likely because of their size. Our results also indicate the disappearance of $\mathrm{HBc}$ from the nucleus at a late p.i. time. However, this return of $\mathrm{HBc}$ does not appear to be affected by cell division, because nondividing BHK-21 cells pre-treated with mitomycin $\mathrm{C}$ did not differ in $\mathrm{HBc}$ localization compared to untreated cells (data not shown). Moreover, alphaviral vectors, including pSFV1, are known to be cytostatic; thus, no cell division should occur during $\mathrm{HBc}$ protein synthesis and transportation. Ad- 
ditionally, SFV induces apoptosis at a late p.i. time (2-3 days). The presence of nuclear export signals in the $\mathrm{HBc}$ protein was recently proposed by $\mathrm{Li}$ and co-authors (Li et al., 2010). Although the mechanism of $\mathrm{HBc}$ translocation is unknown, we can assume that the induction of apoptosis at a late p.i. time may lead to the activation of cellular transporters to accomplish $\mathrm{HBc}$ retrotransport to the cytoplasm.

No major difference was found with regard to $\mathrm{HBc}$ localization when expressed by recombinant pSFV1/HBVpgRNA and $\mathrm{pSFV} 1 / \mathrm{HBc}$ viruses. However, in the case of pgRNA, the number of cells with cytoplasmic plus cytoplasmic/nuclear localization (55\%) was significantly higher compared to $\mathrm{HBc}$ gene expression alone (6\%) $24 \mathrm{hr}$ p.i. These results indicate the retention of $\mathrm{HBc}$ in the cytoplasm of pgRNA-expressing cells. We have previously shown that pgRNA expression from the pSFV1 vector achieves the synthesis of the $\mathrm{HBc}$ protein and also all three variants of envelope proteins, possibly through a ribosome leaky scanning mechanism (Zajakina et al., 2004). In the present study, we performed double anti-HBc and anti-HBs immunostaining and found a colocalization of these proteins in the cytoplasm. Thus, we may conclude that $\mathrm{HBc} / \mathrm{HBs}$ interaction partially prevents $\mathrm{HBc}$ nuclear transport. Surprisingly, not all $\mathrm{HBc}$-expressing cells demonstrated anti-HBs staining, which was possibly associated with a low HBs protein expression level.

Therefore, our experimental model based on a replicationdefective pSFV1 vector is a new tool for the investigation of $\mathrm{HBc}$ intracellular transport. The most interesting observation described herein is $\mathrm{HBc}$ retrotransport from the nucleus to the cytoplasm. Until now, $\mathrm{HBc}$ nuclear translocation has been studied using an artificial model based on digitonin-permeabilized mammalian cells, which does not allow the investigation of $\mathrm{HBc}$ export from the nucleus. In the system proposed here, the nuclear export signals recently identified in $\mathrm{HBc}$ could be tested in a broad range of eukaryotic cells, including human hepatoma cells, which can be efficiently infected with recombinant alphaviruses. Similar $\mathrm{HBc}$ localization results were observed in the human hepatoma cell lines Huh7 and HepG2 (data not shown) in addition to BHK-21 cells. However, as this cell line is most convenient for propagation and alphaviral infection, we propose the use of BHK-21 cells for HBc transport studies. Additionally, the proposed system is independent of the nuclear delivery of HBV genetic material and can be used in non-dividing cells. Accordingly, resting cells can be analyzed for the intracellular distribution of HBV proteins in order to elucidate the molecular and functional roles of these proteins.

Acknowledgements. This work was supported by the grants ERDF No. 2010/0230/2DP/2.1.1.1.0/10/APIA/VIAA/075, LZP387/2012 and national program "Biomedicine". The authors thank N. Garbusheva, D. Pjanova, and I. Timofejeva for excellent technical assistance, and P. Pumpens and M. Kann for useful discussions.

\section{References}

Beck J, Nassal M (2007): Hepatitis B virus replication. World J. Gastroenterol. 13, 48-64. http://dx.doi.org/10.3748/ wjg.v13.i1.48

Bruss V (2007): Hepatitis B virus morphogenesis. World J. Gastroenterol. 13, 65-73. http://dx.doi.org/10.3748/wjg. $\underline{\mathrm{v} 13.11 .65}$

Chu CM, Liaw YF (1995): Simultaneous acute hepatitis B virus and hepatitis $\mathrm{C}$ virus infection leading to fulminant hepatitis and subsequent chronic hepatitis C. Clin. Infect. Dis. 20, 703-705. http://dx.doi.org/10.1093/clinids/20.3.703

Crowther RA, Kiselev NA, Bottcher B, Berriman JA, Borisova GP, Ose V, Pumpens P (1994): Three-dimensional structure of hepatitis B virus core particles determined by electron cryomicroscopy. Cell 77, 943-950. http://dx.doi. org/10.1016/0092-8674(94)90142-2

Ganem D, Prince AM (2004): Hepatitis B virus infection--natural history and clinical consequences. N. Engl. J. Med. 350, 1118-1129. http://dx.doi.org/10.1056/NEJMra031087

Gowans EJ, Burrell CJ, Jilbert AR, Marmion BP (1985): Cytoplasmic (but not nuclear) hepatitis B virus (HBV) core antigen reflects HBV DNA synthesis at the level of the infected hepatocyte. Intervirology 24, 220-225. http://dx.doi. org/10.1159/000149646

Kozlovska T, Zajakina A, Ose V, Bruvere R, Aleksejeva J, Pumpen P, Garoff H (2004): Synthesis of all hepatitis B structural proteins in the Semliki Forest virus expression system. Env. Exp. Biol. 150, 869-873, W154.

Li HC, Huang EY, Su PY, Wu SY, Yang CC, Lin YS, Chang WC, Shih C (2010): Nuclear export and import of human hepatitis B virus capsid protein and particles. PLoS Pathog. 6, e1001162. http://dx.doi.org/10.1371/journal. ppat.1001162

Liljestrom P, Garoff H (1991): A new generation of animal cell expression vectors based on the Semliki Forest virus replicon. Biotechnology (N.Y.) 9, 1356-1361. http:// dx.doi.org/10.1038/nbt1291-1356

Michalak T, Nowoslawski A (1977): Hepatitis B virus in nucleoli of liver cells. N. Engl. J. Med. 297, 787-788. http://dx.doi. org/10.1056/NEJM197710062971414

Naoumov NV, Portmann BC, Tedder RS, Ferns B, Eddleston AL, Alexander GJ, Williams R (1990): Detection of hepatitis $B$ virus antigens in liver tissue. A relation to viral replication and histology in chronic hepatitis B infection. Gastroenterology 99, 1248-1253.

Patient R, Hourioux C, Roingeard P (2009): Morphogenesis of hepatitis $\mathrm{B}$ virus and its subviral envelope particles. Cell Microbiol. 11, 1561-1570. http://dx.doi.org/10.1111/ j.1462-5822.2009.01363.x

Peppa D, Maini MK (2012): Pathogenesis of hepatitis B virus infection and potential for new therapies. Br. J. Hosp. Med. 73, 581-584.

Petit MA, Pillot J (1985): HBc and HBe antigenicity and DNAbinding activity of major core protein P22 in hepatitis $\mathrm{B}$ virus core particles isolated from the cytoplasm of human liver cells. J. Virol. 53, 543-551. 
Rabe B, Delaleau M, Bischof A, Foss M, Sominskaya I, Pumpens P, Cazenave C, Castroviejo M, Kann M (2009): Nuclear entry of hepatitis B virus capsids involves disintegration to protein dimers followed by nuclear reassociation to capsids. PLoS Pathog. 5, e1000563. http://dx.doi. org/10.1371/journal.ppat.1000563

Schmitz A, Schwarz A, Foss M, Zhou L, Rabe B, Hoellenriegel J, Stoeber M, Pante N, Kann M (2010): Nucleoporin 153 arrests the nuclear import of hepatitis B virus capsids in the nuclear basket. PLoS Pathog. 6, e1000741. http:// dx.doi.org/10.1371/journal.ppat.1000741

Serinoz E, Varli M, Erden E, Cinar K, Kansu A, Uzunalimoglu O, Yurdaydin C, Bozkaya H (2003): Nuclear localization of hepatitis $\mathrm{B}$ core antigen and its relations to liver injury, hepatocyte proliferation, and viral load. J. Clin. Gastroenterol. 36, 269-272. http://dx.doi.org/10.1097/00004836$\underline{200303000-00016}$
Vasilevska J, Skrastina D, Spunde K, Garoff H, Kozlovska T, Zajakina A (2012): Semliki Forest virus biodistribution in tumor-free and 4T1 mammary tumor-bearing mice: a comparison of transgene delivery by recombinant virus particles and naked RNA replicon. Cancer Gene Ther. 19, 579-587. http://dx.doi.org/10.1038/cgt.2012.37

Zajakina A, Kozlovska T, Bruvere R, Aleksejeva J, Pumpens P, Garoff $H$ (2004): Translation of hepatitis B virus (HBV) surface proteins from the HBV pregenome and precore RNAs in Semliki Forest virus-driven expression. J. Gen. Virol. 85, 3343-3351. http://dx.doi.org/10.1099/vir.0.80388-0

Zajakina A, Niedre-Otomere B, Alekseeva J, Kozlovska T (2008): Alphaviruses: multiplicity of vectors and their promising application as vaccines and cancer therapy agents. Medicinal Protein Engineering, book chapter 519-550. 